\title{
PEO coated magnetic nanoparticles for biomedical application
}

\author{
A. Aqil ${ }^{\mathrm{a}}$, S. Vasseur ${ }^{\mathrm{b}}$, E. Duguet ${ }^{\mathrm{b}}$, C. Passirani ${ }^{\mathrm{c}}$, J.P. Benoît ${ }^{\mathrm{c}}$, A. Roch ${ }^{\mathrm{d}}$, R. Müller ${ }^{\mathrm{d}}$, R. Jérôme ${ }^{\mathrm{a}}$, C. Jérôme ${ }^{\mathrm{a}}$ \\ ${ }^{a}$ Center for Education and Research on Macromolecules (CERM), University of Liège Sart-Tilman, B6, 4000 Sart-Tilman, Liège, Belgium \\ ${ }^{b}$ Bordeaux Institute of Condensed Matter Chemistry (ICMCB) 87, Avenue du Docteur Albert Schweitzer, F-33 608 PESSAC, France \\ 'Ingénierie de la Vectorisation Particulate (Inserm) 10, rue André Boquel 49100 ANGERS, France \\ ${ }^{d}$ NMR and Molecular Imaging Laboratory 24, Avenue du Champ de Mars B-7000 Mons, Belgium
}

\section{Abstract}

This paper reports on the preparation, characterization and stealthiness of superparamagnetic nanoparticles (magnetite $\mathrm{Fe}_{3} \mathrm{O}_{4}$ ) with a $5 \mathrm{~nm}$ diameter and stabilized in water $(\mathrm{pH} \geq 6.5$ ) by a shell of water-soluble poly(ethylene oxide) (PEO) chains. Two types of diblock copolymers, i.e., poly(acrylic acid)-b-poly(ethylene oxide), PAA-PEO, and poly(acrylic acid)-b-poly(acrylate methoxy poly(ethyleneoxide)), PAA-PAMPEO, were prepared as stabilizers with different compositions and molecular weights. At $\mathrm{pH} \geq 6.5$, the negatively ionized PAA block interacts strongly with the positively-charged nanoparticles, thus playing the role of an anchoring block. Aggregates of coated nanoparticles were actually observed by dynamic light scattering (DLS) and transmission electron microscopy (TEM). The hydrodynamic diameter was in the 50-100 nm range and the aggregation number (number of nanoparticles per aggregate) was lying between several tens and hundred. Moreover, the stealthiness of these aggregates was assessed "in vitro" by the hemolytic CH50 test. No response of the complement system was observed, such that biomedical applications can be envisioned for these magnetic nanoparticles. Preliminary experiments of magnetic heating $(10 \mathrm{kA} / \mathrm{m} ; 108 \mathrm{kHz})$ were performed and specific absorption rate varied from 2 to $13 \mathrm{~W} / \mathrm{g}\left(\mathrm{Fe}_{\mathrm{Fe}}\right)$.

Keywords: Magnetic nanoparticles RAFT polymerization Hyperthermia Stealth behavior

\section{Introduction}

Magnetic nanomaterials have great promise in the design of electronic and electrical devices [1], sensors [2], electromagnetic shielders and materials for high-density digital storage [3]. Biomedical applications are under current investigation, such as retinal detachment therapy [4], cell separation methods $[5,6]$, tumor hyperthermia [7], improved MRI diagnosis [8-10], radioactive therapies [11-13] and magnetic field-guided carriers for localizing drugs. In biomedicine, for magnetic nanoparticles to be instrumental tracers, they have to be functionalized by ligands, peptides or oligonucleotides in order to reach target-cells and tissues [14]. These surface modifications, however, result often in the undesired aggregation/precipitation of the particles. In case of irreversible aggregation, the nanoparticles loose their very specific properties, for instance their ability to "get close" to biological entities [15]. This explains why the colloidal stability of inorganic nanoparticles has been a key issue in the recent years.

In this respect, magnetic nanoparticles have been dispersed in carrier fluids, i.e., associated to low molecular weight or polymeric surfactants. These fluidic dispersions, known as "ferrofluids", must resist the magnetic attractive forces combined with inherently large surface energies (>100 dyn/cm) $[16,17]$.

Another issue is the biocompatibility and durability of the magnetic nanoparticles in biological environments. For instance, their sensitivity to oxidation can lead to formation of antiferromagnetic oxides, thus to the loss of the magnetic response. Iron oxides, such as magnetite $\left(\mathrm{Fe}_{3} \mathrm{O}_{4}\right)$ and maghemite $\left(\gamma-\mathrm{Fe}_{2} \mathrm{O}_{3}\right)$, combine a reasonable stability against oxidation and a strong ferromagnetic behaviour. Moreover, the lethal dose of magnetite is high (LD50 in rats, $400 \mathrm{mg} / \mathrm{kg}$ ), and polymer-coated magnetite would not be toxic according to acute or subacute testing on animals $[7,17,18]$.

Magnetite particles are commonly prepared by condensation of divalent and trivalent iron salts in the presence of hydroxide. Electrostatic and steric (entropie) stabilizers have to be used to prevent agglomeration for occurring [19-30]. Steric stabilization of magnetite nanoparticles by poly(ethylene oxide) (PEO) chains is of the utmost importance for biomedical applications. Recently, the preparation of PEO coated magnetic nanoparticles have been reported by several groups [24]. Liu et al. have synthesized aqueous suspension of superparamagnetic iron oxide nanoparticles coated with diblock (graft) copolymer, poly(ethylene glycol) monomethyl ether- $b(\mathrm{~g})$ poly(glycerol monoacrylate) (PEG-b-PGA). In the suspension, PGA was chemisorbed tightly on the nanoparticle surface by coordinating its 1,2-diols to the Fe atoms and the PEG block extended into the water matrix [24a,b]. 
Jeong et al. used a PEG-silane copolymer [poly(3-trimethoxysilyl) propyl methacrylate]-r-[poly (ethylene glycol) methyl ether methacrylate] where the silane group is a surface anchoring moiety [24c]. Gao et al. have succeeded to prepare biocompatible $\mathrm{Fe}_{3} \mathrm{O}_{4}$ NPs by covalently modifying NPs with monocarboxyl-terminated PEG via its carboxylic group [24d]. Indeed, PEO is the most effective material for making nanoparticles stealthy, i.e., not or hardly detectable by the immune system either through humoral reactions or, at the cell level, through opsonins. The reason is that the highly hydrated and flexible PEO chains can form a steric barrier against the adsorption of proteins at the nanoparticle surface [31]. Whenever, the proteins are no longer adsorbed (opsonization), the phagocytosis of the nanoparticles is avoided and their lifetime is increased in the blood circulation [32]. The components of the complement system, which is part of the immune system, are thought to cooperate with the other opsonins in making foreign surfaces prone to phagocytosis [33]. Because of this important role of the complement system, quantitative consumption of the proteins of the human complement system, as consequence of adsorption onto nanoparticles, is a stealthiness criterion. Basically, in an established test (CH50 test), the hemolytic capacity of the residual, non-adsorbed complement proteins is evaluated, after contact of human serum with different amounts of nanoparticles [34,35].

This paper aims at reporting on the preparation of novel, hydrophilic, diblock copolymers, i.e., poly(acrylic acid)- $b$-poly(ethyleneoxide), PAA-PEO, and poly(acrylic acid)- $b$-poly(acrylate methoxy poly(ethyleneoxide)), PAA-PAMPEO, by reversible addition fragmentation chain transfer (RAFT) polymerization. Magnetite nanoparticles were prepared in water $(\mathrm{pH} \geq 6.5)$ and stabilized by these copolymers. The stealthiness of these suspensions was established by the CH50 test. Last but not least, they can generate heat when submitted to an alternating magnetic field, which is the basic concept of magnetic hyperthermia.

\section{Materials and methods}

\subsection{Materials}

Toluene was dried by refluxing over the sodium/benzophenone complex and distilled under nitrogen before use. Poly(ethylene oxide) monomethyl ether (MPEO-OH), $(\mathrm{Mn}=2000 \mathrm{~g} / \mathrm{mol})$, was purchased from SIGMA. Acrylic acid (AA) was purified by distillation under reduced pressure. $\alpha$-Acrylate $\omega$-methoxy poly (ethylene oxide) (AMPEO, Mn = $454 \mathrm{~g} / \mathrm{mol}$ ) purchased from Aldrich, dimethylformamide (DMF), azo-bis-isobutyronitrile (AIBN), dimethylaminopyridine (DMAP) and $N$-dicyclohexylcarbodiimide (DCC; Aldrich, 99\%) were used as received. 2-dodecylsulfanylthiocarbonylsulfanyl-2-methyl propionic acid (DMP) was synthesized according to Lai et al. [39]. $\mathrm{FeCl}_{3} 6 \mathrm{H}_{2} \mathrm{O}$ and $\mathrm{FeCl}_{2} 4 \mathrm{H}_{2} \mathrm{O}$ (Aldrich) were used without further purification. Water MiliQ was deoxygenated for at least 30 min with ultra-high-purity nitrogen (99.9+\%). Hydrochloric acid (Aldrich) was used as a $25 \% \mathrm{v} / \mathrm{v}$ aqueous solution.

\subsection{Synthesis of PAA-PEO diblock copolymer}

(i) Synthesis of PEO-RAFT macroinitiator, $\alpha$-methoxy- $\omega$-DMP-poly(ethylene oxide) (PEO-RAFT) was synthesized by esterification of the hydroxyl end-group of the mono-methoxy poly(ethylene oxide) by DMP, which is a typical RAFT agent. A representative reaction was carried out as follows. $\alpha$-methoxy- $\omega$-hydroxypoly(ethylene oxide) (MPEO-OH) with a molecular weight of $2000 \mathrm{~g} / \mathrm{mol}(10 \mathrm{~g}$; $5 \mathrm{mmol}$ ) was added into a 100 $\mathrm{mL}$ two-necked flask equipped with a stirrer. The MPEO-OH was dried by three azeotropic distillations of toluene and finally dissolved in $50 \mathrm{~mL}$ dry toluene. DMP (1.1 equiv., $2 \mathrm{~g})$, DCC (1.1 equiv., $1.13 \mathrm{~g})$ and DMAP ( 1.1 equiv., $0.67 \mathrm{~g}$ ) were then added, and the flask was heated in an oil bath at $70{ }^{\circ} \mathrm{C}$ overnight. PEO-RAFT was collected by precipitation in ether at $0{ }^{\circ} \mathrm{C}$ and then dried at $40{ }^{\circ} \mathrm{C}$ in vacuo for $24 \mathrm{~h}$. The functionalization yield was $88 \%$ as determined by ${ }^{1} \mathrm{H}$ NMR $\left(\mathrm{CDCl}_{3}\right)$ from the relative intensity of the resonances at $\delta=4.21 \mathrm{ppm}$ (t, $2 \mathrm{H}, \mathrm{CH}_{2} \mathrm{OCO}$ ) and $\delta=0.83 \mathrm{ppm}\left(\mathrm{t}, 3 \mathrm{H}, \mathrm{CH}_{2}-\mathrm{CH}_{3}\right.$ ). (ii) Synthesis of PAA-PEO diblock. PAA-PEO was prepared by conventional RAFT polymerization with PEO-RAFT used as a macroinitiator (Scheme 1). In a previously flamed three-neck flask, distilled AA (2.0 g), PEO-RAFT (0.5 g, $\left.2.11 \times 10^{-4} \mathrm{~mol}\right)$ and AIBN (3.5 mg, $2.11 \times 10^{-5} \mathrm{~mol}$ ) were dissolved in $20 \mathrm{~mL}$ of DMF. The solution was degassed by three freeze-thaw-evacuation cycles, and then transferred to an oil bath at $75^{\circ} \mathrm{C}$. After $3 \mathrm{~h}$, the crude product was precipitated in diethyl ether. This precipitation was twice repeated. The final copolymer was slightly-yellow and characterized by ${ }^{1} \mathrm{H}$ NMR (400 MHz; DMSO). The $\alpha$-proton of the AA units was observed at $2.20 \mathrm{ppm}(\mathrm{CH}-\mathrm{COOH}, \mathrm{m})$ and the methyl proton of the RAFT end-group at $0.83 \mathrm{ppm}\left(\mathrm{CH}_{2}-\mathrm{CH}_{3}, \mathrm{t}\right)$. 


\subsection{Synthesis of PAA-PAMPEO block copolymer}

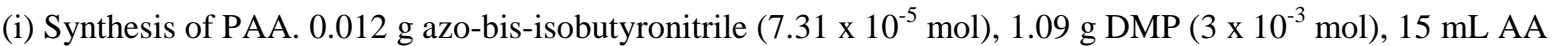
$\left(1.98 \times 10^{-1} \mathrm{~mol}\right)$ and $15 \mathrm{~mL}$ DMF were mixed in a $250 \mathrm{~mL}$ Schlenk flask. The mixture was degassed by four freeze-pump-thaw cycles. This reaction mixture was heated in an oil bath at $70{ }^{\circ} \mathrm{C}$ for $4 \mathrm{~h}$. The polymer was precipitated by addition of the solution into ether, and dried in vacuo up to constant weight. The molecular weight was determined by ${ }^{1} \mathrm{H}$ NMR in DMSO $\left(\mathrm{Mn}=3 \times I_{2.44} / I_{0.8}+364\right)$, where $I_{0.8}$ and $I_{2.44}$ are the intensity of the proton resonances at $0.83 \mathrm{ppm}\left(\mathrm{CH}_{3}-\mathrm{C}_{11} \mathrm{H}_{22}, \mathrm{t}\right)$ and $2.20 \mathrm{ppm}(\mathrm{CH}-\mathrm{COOH}, \mathrm{m})$, respectively. Polydispersity was measured by size exclusion chromatography (SEC) in DMF. (ii) Synthesis of PAA- $b$-PAMPEO. A mixture of $0.3 \mathrm{~g}$ trithiocarbonate-capped PAA $\left(10^{-4} \mathrm{~mol} ; \mathrm{Mn}(\mathrm{NMR})=3000\right.$ and $\left.\mathrm{Mw} / \mathrm{Mn}=1.10\right), 1.5 \mathrm{~g}$ AMPEO $(0.028$ $\mathrm{mol}), 1.64 \times 10^{-3} \mathrm{~g}$ AIBN $\left(10^{-5} \mathrm{~mol}\right)$ and $10 \mathrm{~mL}$ DMF was degassed by four freeze-pump-thaw cycles and heated in an oil bath at $80{ }^{\circ} \mathrm{C}$ for $3 \mathrm{~h}$. The copolymer was precipitated into ether and dried in vacuo up to constant weight. The molecular weight of the second block was determined by ${ }^{1} \mathrm{H}$ NMR in DMSO $\left(\mathrm{Mn}=3 I_{4.1} / 2 I_{0.8}+\right.$ $364)$, where $I_{0.8}$ and $I_{44}$ are the intensity of the proton resonances at $0.83 \mathrm{ppm}\left(\mathrm{CH}_{3}-\mathrm{C}_{\mathrm{n}} \mathrm{H}_{22}, \mathrm{t}\right)$ and $4.1 \mathrm{ppm}(\mathrm{CH}-$ $\mathrm{COOCH} 2, \mathrm{~m})$, respectively. Polydispersity was determined by SEC in DMF.

Scheme 1. General strategy for the synthesis of the PAA-PEO and PAA-PAMPEO copolymers, respectively.

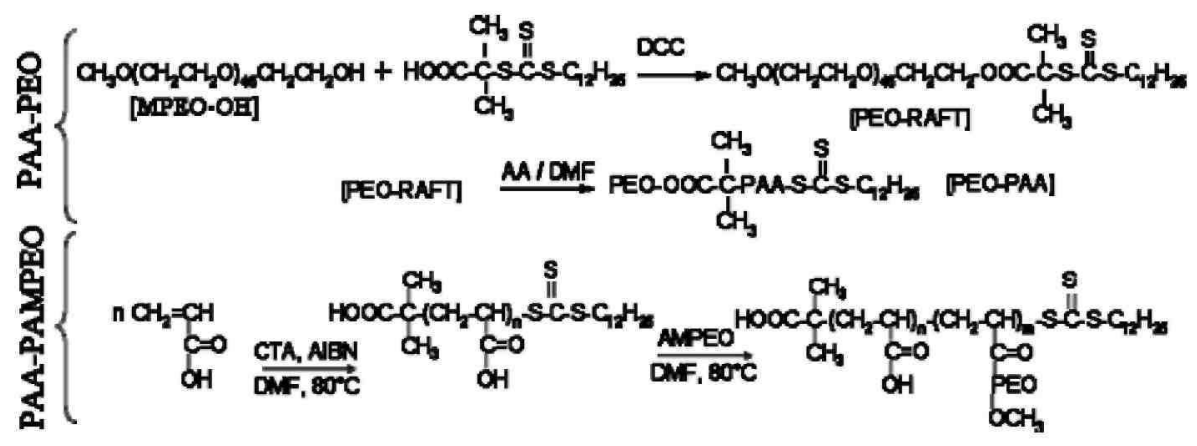

\subsection{Synthesis of $\mathrm{Fe}_{3} \mathrm{O}_{4}$ nanoparticles}

The magnetite nanoparticles were prepared by the Massart process [19]. All the solutions were deoxygenated just prior to use in order to minimize parasitic oxidation. Required amounts of $\mathrm{FeCl}_{3} \cdot 6 \mathrm{H}_{2} \mathrm{O}(40 \mathrm{~mL}, 1 \mathrm{M}$ in $\mathrm{HC} 1$ solution $2 \mathrm{M})$ and $\mathrm{FeCl}_{2} 4 \mathrm{H}_{2} \mathrm{O}(10 \mathrm{~mL}, 2 \mathrm{M}$ in $\mathrm{HC} 1$ solution $2 \mathrm{M})$ were mixed in an additional funnel and added dropwise within $15 \mathrm{~min}$ to an alkaline solution $(400 \mathrm{~mL}, 0.75 \mathrm{M})$ at $100{ }^{\circ} \mathrm{C}$ under magnetic stirring. The solution quickly turned black as result of magnetite formation. The magnetite particles were let to grow for $1 \mathrm{~h}$ under stirring and nitrogen. After cooling down to room temperature, they were collected with a permanent magnet, and the supernatant was discarded by decantation. Salt excess and $\mathrm{NaCl}$ byproduct were eliminated by suspending the particles within $100 \mathrm{~mL}$ of nitric acid for $10 \mathrm{~min}$. This purification procedure was 3 times repeated. Finally, the purified uncoated particles were dispersed within deionized water and dialyzed (Spectra pore 7, MWCO 8000) against water ( $\mathrm{pH} \sim 4)$ for 2 days, the water being replaced twice a day. Particle aggregates were removed by centrifugation for $30 \mathrm{~min}$, which was repeated until no insoluble was deposited at the bottom of the tube. Approximately $6 \mathrm{mg} \mathrm{Fe} \mathrm{O}_{4} / \mathrm{mL}$ was collected (checked by volumetric titration).

\subsection{Coating of the $\mathrm{Fe}_{3} \mathrm{O}_{4}$ nanoparticles by a block copolymer}

A representative recipe (thus, whatever the block copolymer) was as follows. Fifty milligrams of block copolymer was dissolved in $3 \mathrm{~mL}$ double-distilled water in a $20 \mathrm{~mL}$ round-bottom flask equipped with a magnetic stirring bar. The $\mathrm{pH}$ was adjusted to $\mathrm{pH} \sim 6.5 .3 \mathrm{~mL}$ of the uncoated $\mathrm{Fe}_{3} \mathrm{O}_{4}$ suspension $(6 \mathrm{mg} / \mathrm{mL}, \mathrm{pH}$ $\sim$ ) were then added dropwise to the copolymer solution.

\subsection{Complement consumption}

Complement activation was measured as the lytic capacity of a normal human serum (NHS) towards antibodysensitized sheep erythrocytes after exposure to the nanoparticles. Aliquots of NHS were incubated with increasing amounts of nanoparticles. The amount of serum, able to haemolyse $50 \%$ of a fixed number of the sheep erythrocytes after exposure to the nanoparticles, was determined ("CH50 units") for each sample. NHS 
was provided by the "Etablissement Français du Sang" (Angers, France) and stored as aliquots at $-80{ }^{\circ} \mathrm{C}$ until use. Veronal-buffered saline containing $0.15 \mathrm{mM} \mathrm{Ca}^{2+}$ and $0.5 \mathrm{mM} \mathrm{Mg}^{2+}(\mathrm{VBS}++)$ was prepared as reported elsewhere [32b]. Firstly, sheep erythrocytes were sensitized by rabbit anti-sheep erythrocytes antibodies (Sérum hémolytique, Biomérieux, Marcy-l'Etoile, France) and diluted by the veronal-buffered saline at a final concentration of 2.109 cells $/ \mathrm{mL}$ in VBS++. Increasing amounts of the particle suspension were added to NHS diluted in VBS++ such that the final dilution of NHS in the mixture was $1 / 4(\mathrm{v} / \mathrm{v})$ in a final volume of $1 \mathrm{~mL}$ After $1 \mathrm{~h}$ of incubation at $37{ }^{\circ} \mathrm{C}$ under gentle agitation, the suspension was diluted $1 / 25(\mathrm{v} / \mathrm{v})$ in VBS++, and aliquots of 8 different dilutions were added to a given volume of sensitized sheep erythrocytes. After 45 min of incubation at $37^{\circ} \mathrm{C}$, the reaction mixture was slightly centrifuged at $2000 \mathrm{rpm}$ for $10 \mathrm{~min}$. The absorption of the supernatant was determined at $414 \mathrm{~nm}$ with a microplate reader (Multiskan Anscent, Labsystems SA, CergyPontoise, France) and compared to the results obtained with control serum in order to evaluate the amount of hemolysed erythrocytes. Positive and negative controls were made in each series of experiments in order to account for any difference in the hemoglobin response from a given erythrocyte preparation. Furthermore, corrections for particle light scattering and spontaneous erythrocyte hemolysis were estimated by UV/VIS measurements using blanks containing only particles and only erythrocytes, respectively. In order to compare nanoparticles of different average diameters, their surface area was calculated as follows: $\mathrm{S}=3 \mathrm{~m} / r \rho$, where $\mathrm{S}$ is the surface area $\left[\mathrm{cm}^{2}\right], m$ the weight $[\mu \mathrm{g}]$ in $1 \mathrm{~mL}$ of suspension, $r$ the average radius $[\mathrm{cm}]$ determined by DLS, and $p$ the volumetric mass $\left[\mu \mathrm{g} / \mathrm{cm}^{3}\right]$ of the nanoparticles estimated at $106 \mu \mathrm{g} / \mathrm{cm}^{3}$. The experimental data were the average of three independent experiments with a $10 \%$ standard deviation.

\subsection{Calorimetric determination of specific absorption rates (SAR)}

For the calorimetric determination of SAR, the iron oxide suspensions were thermally isolated in a vessel and placed into a coil. Temperature changes vs. time of exposure to an alternating magnetic field (amplitude, $10 \mathrm{kA} / \mathrm{m}$; frequency, $108 \mathrm{kHz}$ produced by a Celes inductor C97104) were automatically registered with an optical fibre connected to a multimeter.

\subsection{Methods}

Samples were analyzed by ${ }^{1} \mathrm{H}$ NMR spectroscopy with a Bruker AM 400 apparatus at $25^{\circ} \mathrm{C}$, in deuterated chloroform $\left(\mathrm{CDCl}_{3}\right)$ added with tetramethylsilane as an internal reference. Molecular weight and polydispersity index $(\mathrm{Mw} / \mathrm{Mn})$ were determined by size exclusion chromatography (SEC) WATERS instrument, using a 25 $\mathrm{mM}$ solution of $\mathrm{LiBr}$ in DMF as the eluent at $50{ }^{\circ} \mathrm{C}$. The columns were calibrated with polystyrene standards. The diameter of the micelles was measured by dynamic light scattering (DLS), DLS measurements were performed on a Malvern Instrument Model ZetaSizer Nano ZS. The hydrodynamic diameter and size distribution were calculated by the CONTIN method and data of at least five measurements were averaged for each suspension. The average particle size, size distribution and morphology of the samples were observed by transmission electron microscopy (TEM) with a Philips CM-100 microscope, at an accelerating voltage of 100 $\mathrm{kV}$. Samples were prepared by deposition of one drop of an appropriately diluted solution onto the copper grid coated with Formvar and dried in air before observation. Magnetization of the iron oxide nanoparticles was measured as a function of the applied magnetic field $(\mathrm{H})$ with a SQUID MPMS-5S magnetometer from Quantum design. The hysteresis curve was recorded by changing $\mathrm{H}$ between -6000 and $6000 \mathrm{Oe}$ at $290 \mathrm{~K}$.

\section{Results and discussion}

The major purpose of this work was to develop a methodology for the preparation of highly stable aqueous dispersions of magnetite nanoparticles endowed with protein repellency and thus with stealthiness. Preformed $\mathrm{Fe}_{3} \mathrm{O}_{4}$ nanoparticles were accordingly coated with a biocompatible hydrophilic steric stabilizer, so making their dispersion well-suited to biological fluids. For this purpose, two types of block copolymers, PAA-PEO and PAA-PAMPEO, were considered that consist of an anchoring PAA block towards the $\mathrm{Fe}_{3} \mathrm{O}_{4}$ nanoparticles and a PEO (or PEO containing) hydrophilic block known for particle steric stabilization, biocompatibility and protein repellence. Synthesis of PAA-PEO block copolymers was reported in the scientific literature by either anionic polymerization [36] or atom transfer radical polymerization (ATRP) [37]. Nevertheless, the anionic pathway was time consuming, because AA could not be polymerized without protection. tert-Butylacrylate was the usual substitute, and an additional step was needed to convert the polyacrylate chains into PAA by hydrolysis. Moreover, the major drawback of ATRP is an organometallic catalysis, which may be source of unacceptable contamination for biomedical applications. 


\subsection{Copolymers synthesis}

In this work, the envisioned block copolymers were prepared by RAFT, with 2dodecylsulfanylthiocarbonylsulfanyl-2-methyl propionic acid (DMP) as a RAFT agent. RAFT is indeed an organic process of controlled radical polymerization technique, applicable to a wide range of monomers, under mild reaction conditions [38]. Lai et al. reported the synthesis of DMP and used it successfully in the controlled polymerization of acrylic acid [39].

Scheme 1 shows the two-step technique used for the synthesis of PAA-PEO copolymers. Monomethoxy poly (ethylene oxide) $(\mathrm{Mn}=2000 \mathrm{~g} / \mathrm{mol})$ was first end-capped by the RAFT agent, by esterification of the hydroxyl end-group with the carboxylic acid function of DMP. The yield (88\%) was determined by ${ }^{1} \mathrm{H}$ NMR (see experimental section). Polymerization of acrylic acid was initiated by the PEO-RAFT macro agent in DMF, in the presence of AIBN. Two diblock copolymers of different molecular weights and compositions were synthesized with a narrow molecular weight distribution (Table 1, entries 1-2).

RAFT was also considered for the sequential polymerization of AA and AMPEO, in order to replace the linear PEO block of the previous diblocks by PEO with a comb-like architecture. The reason for the synthesis of the two series of diblock copolymers was to investigate the possible impact of the architecture of the PEO shell around the magnetite particles on the stability of their dispersion and on their stealthiness.

Fig. 1 shows that the AMPEO radical polymerization is well controlled when initiated by azo-bis-isobutyronitrile $(\mathrm{AIBN})$ in the presence of DMP, in DMF at $80{ }^{\circ} \mathrm{C}([\mathrm{AM}-\mathrm{PEO}] /[\mathrm{DMP}] /[\mathrm{AIBN}]=440: 20: 1$, $[\mathrm{AMPEO}]=0.5 \mathrm{M})$. The apparent molecular weight that was determined by ${ }^{1} \mathrm{H}$ NMR increases linearly with monomer conversion (Fig. 1a). The polydispersity index (Mw/Mn) for all the samples is lower than 1.15. The time dependence of $\ln \left([\mathrm{M}]_{0} /[\mathrm{M}]\right)$ is linear, indicating a constant concentration of radicals in the polymerization medium (Fig. 1b). All these observations confirm that DMP is quite an appropriate chain transfer agent for the controlled polymerization of AMPEO.

Copolymers consisting of PAMPEO and PAA blocks were synthesized by the sequential RAFT polymerization of AA and AMPEO. The acrylic acid was first polymerized, and the molecular weight of PAA agreed with a controlled process. PAA was precipitated in order to remove the unreacted monomer and used as a macro-RAFT agent for the polymerization of AMPEO. Table 1 lists the copolymers synthesized in this work and used to stabilize magnetite nanoparticles (entries 3-6).

Table 1: Physicochemical characteristics of the nanoparticles prepared in this work

\begin{tabular}{|c|c|c|c|c|c|c|c|c|}
\hline \multirow[t]{2}{*}{ Entry } & \multicolumn{3}{|c|}{ Ligand description } & \multirow{2}{*}{$\begin{array}{c}\mathrm{RH} \\
\mathrm{DLS}\end{array}$} & \multirow[t]{2}{*}{ PI (DLS) } & \multirow{2}{*}{$\begin{array}{l}\text { Zéta potential } \zeta \\
(\mathrm{mV})\end{array}$} & \multirow{2}{*}{$\begin{array}{l}\text { Conductivity } \\
(\mathrm{mS} / \mathrm{cm})\end{array}$} & \multirow{2}{*}{$\begin{array}{c}\mathrm{SAR} \\
\left(\mathrm{W} / \mathrm{g}_{(\mathrm{Fe})}\right)\end{array}$} \\
\hline & $\begin{array}{c}\text { Block } \\
\text { copolymer }\end{array}$ & $\begin{array}{c}\text { DP } \\
\text { (NMR) }\end{array}$ & PI (SEC) & & & & & \\
\hline$\overline{0}$ & - & - & - & - & - & 45.7 & 0.07 & 19.6 \\
\hline 1 & PAA-PEO & $48-45$ & 1.19 & 73.35 & 0.24 & nd & nd & 9.0 \\
\hline 2 & PAA-PEO & $83-45$ & 1.16 & 69.20 & 0.17 & -35.8 & 0.68 & 5.4 \\
\hline 3 & PAA-PAMPEO & $61-11$ & 1.25 & 75.50 & 0.22 & -40.6 & 0.48 & 13.6 \\
\hline 4 & PAA-PAMPEO & $61-21$ & 1.51 & 88.50 & 0.33 & -34.3 & 0.41 & 12.4 \\
\hline 5 & PAA-PAMPEO & $34-110$ & 1.35 & 123.80 & 0.33 & nd & nd & 2.2 \\
\hline 6 & PAA-PAMPEO & $34-66$ & 1.30 & 93.35 & 0.23 & nd & nd & 2.4 \\
\hline
\end{tabular}

Degree of polymerization [DP] and polydispersity index [PI] determined by SEC for the diblock copolymers used as ligands. Hydrodynamic radius $[\mathrm{RH}]$ and polydispersity index of copolymer micelles. Zeta potential $[\zeta]$ and conductivity for neaked magnetite nanoparticles entry $[0]$ and the same stabilized by diblock copolymers entries [1-6]. 
Fig. 1: (a) Conversion dependence of both the number-average molecular weight [ $\mathbf{\square}:$ Mn determined by NMR, $\checkmark:$ theoretical Mn] and polydispersity index [PI] of PAMPEO. RAFT polymerization of AMPEO was initiated by $A I B N$ in the presence of DMP as a transfer agent, in DMF at $80^{\circ} \mathrm{C}$. [AN]/[DMP]/[AIBN] = 440:20:1, $[A M P E O]=0.5 \mathrm{M}$. [the solid line is a guide for eyes], (b) Time dependence of $\ln [[M] \mathrm{d} / \mathrm{M}]]$ for the RAFT polymerization of AMPEO initiated by AIBN in the presence of DMP as a transfer agent, in DMF at $80{ }^{\circ} \mathrm{C}$. $[A M P E O] /[D M P] /[A I B N]=440: 20: 1,[A M P E O]=0.5 M$.
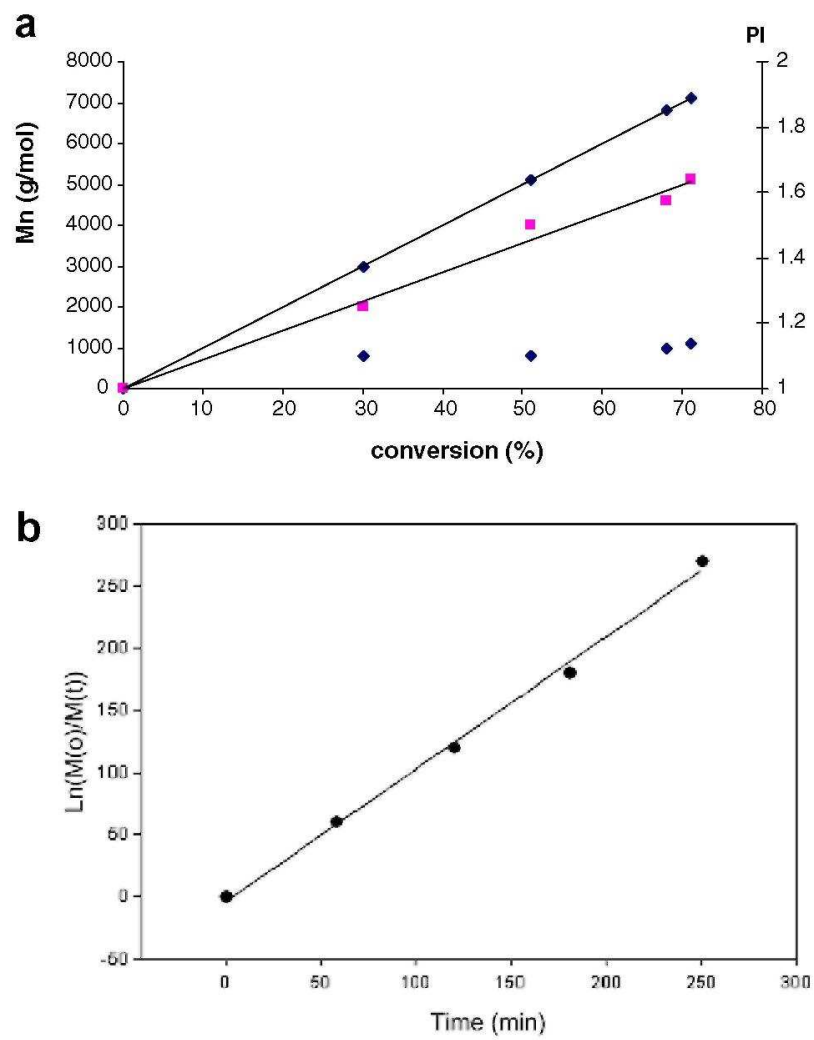

\subsection{Synthesis and stabilization of magnetic nanoparticles}

Magnetite nanoparticles were prepared by co-precipitation of aqueous solutions of $\mathrm{FeCl}_{2}$ and $\mathrm{FeCl}_{3}$ in the presence of sodium hydroxide base $\left(\mathrm{pH}\right.$ 13) salt solutions under nitrogen at room temperature. The $\mathrm{Fe}^{2+} / \mathrm{Fe}^{3+}$ molar ratio was 0.5 for the conversion to be quantitative. After washing by nitric acid, the acid leads to the protonation of the particles and to the formation of an electric double layer around the particles. This peptization phenomenon leads to the formation of highly stable suspension in water, as result of electrostatic repulsions of charged particles. Residual nitric acid was removed by dialysis (Scheme 2). The diameter of the magnetite nanoparticle diameter was $5 \pm 2 \mathrm{~nm}$ as determined by TEM (Fig. 2). The magnetization of the nanoparticles disappeared instantaneously when the external field was suppressed, which indicates that their magnetic remanence and coercivity are close to zero at room temperature. This behavior is typical of superparamagnetic materials, which is desirable for biomedical applications (Fig. 3). The X-ray powder diffraction spectrum of the magnetic nanoparticles is shown in Fig. 4. Five characteristics peaks for $\mathrm{Fe}_{3} \mathrm{O}_{4}$ corresponding to indices (220), (311), (400), (511), and (440) are observed, but the entire peaks of the diffractogram are not very well-defined; they can be indexed either to maghemite or magnetite. It indicates that probably both structures coexist in the ferrofluid. In order to discern if these iron oxide particles are built up of magnetite $\left(\mathrm{Fe}_{3} \mathrm{O}_{4}=2 \mathrm{Fe}^{3+} \mathrm{Fe}^{2+} 4 \mathrm{O}^{2-}\right)$ or maghemite $\left(\mathrm{Fe}_{2} \mathrm{O}_{3}=2 \mathrm{Fe}^{3+} 3 \mathrm{O}^{2-}\right)$, the occurrence of $\mathrm{Fe}^{2+}$ ions was determined by the titration with potassium dichromate $\mathrm{K}_{2} \mathrm{Cr}_{2} \mathrm{O}_{7}$. No significant $\mathrm{Fe}^{2+}$ ion concentration was determined ( $\left.5 \%\right)$, suggesting the maghemite phase as the dominant crystalline phase in the samples. 
Scheme 2: Preparation of magnetite nanoparticles and coating by PAA containing block copolymers.

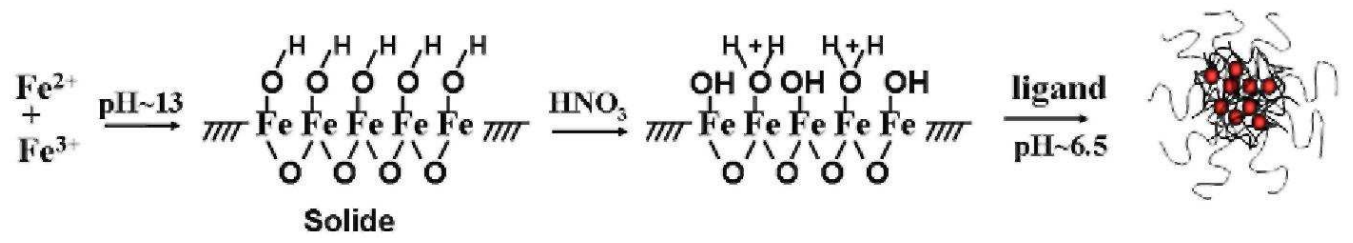

Fig. 2: TEM images of iron oxide nanoparticles [a] uncoated, [b1-b2] coated by $P A A_{48}-P E O_{45}$ (entry 1), [c1-c2] coated by $P A A_{34}-P A M P E O_{66}($ entry 6).
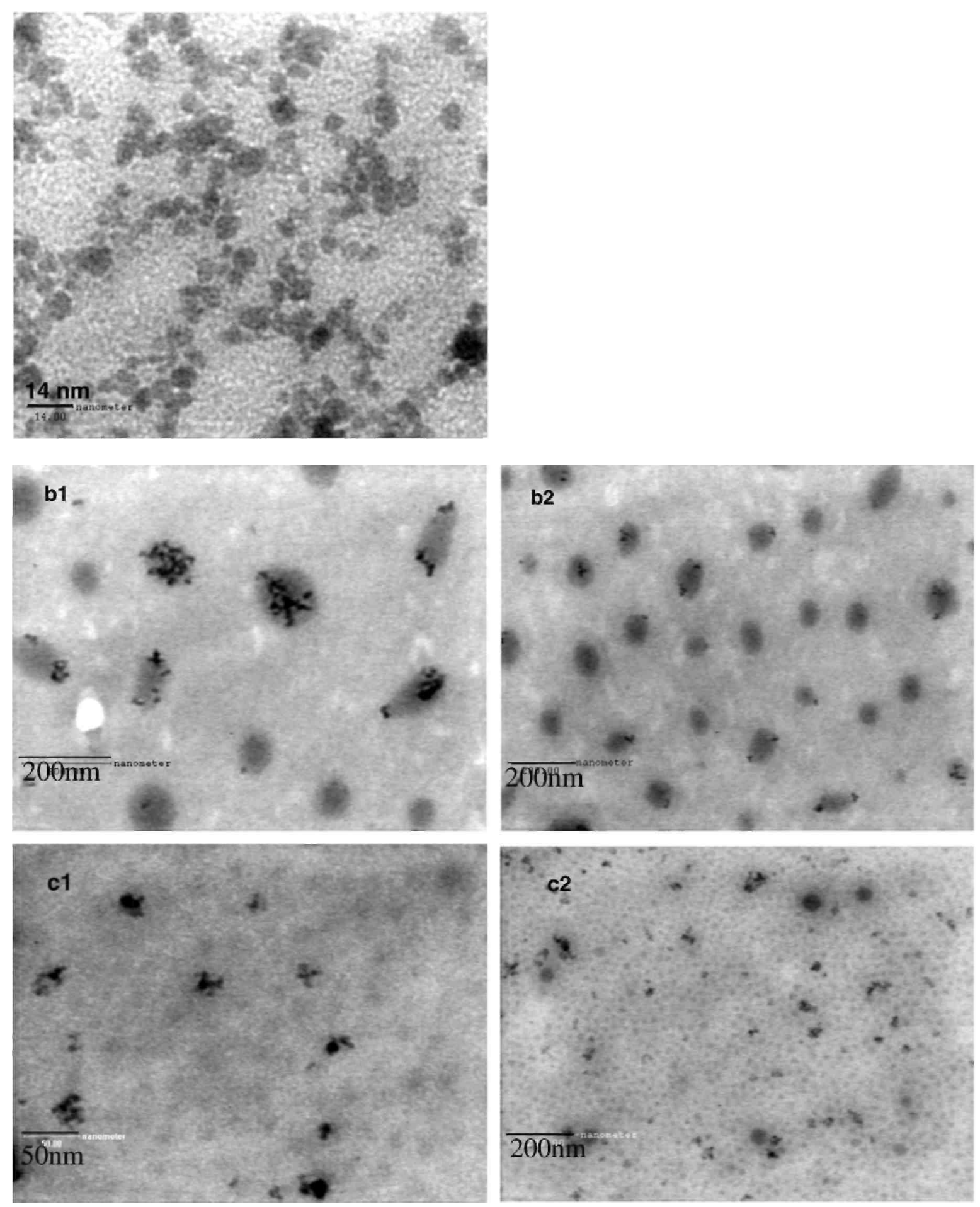
Fig.3: Magnetization curve of magnetite nanoparticles at room temperature.

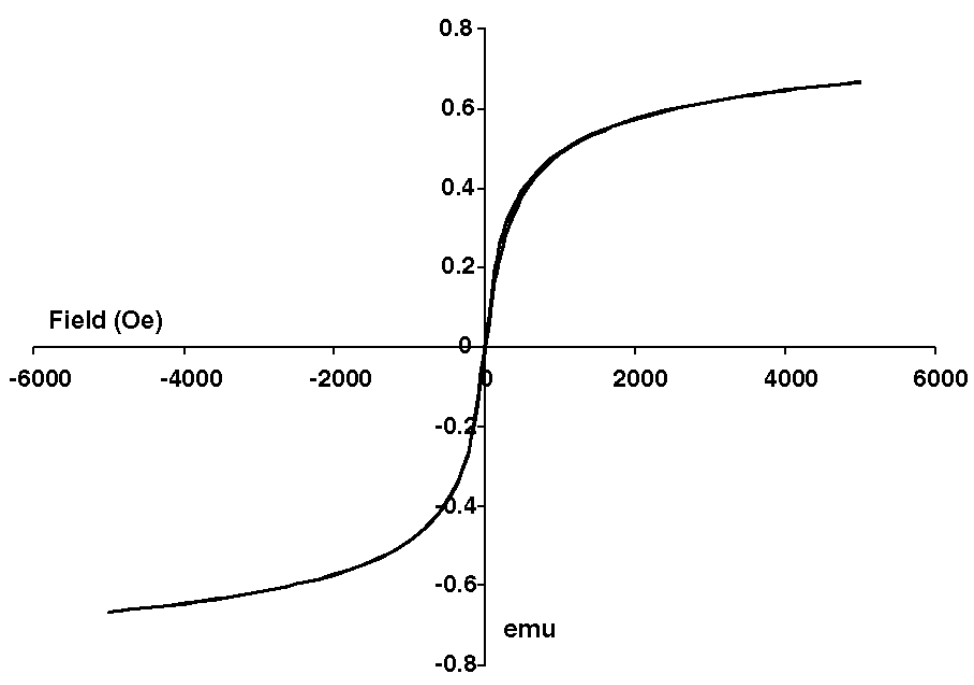

Fig 4: XRD patterns of iron oxide nanoparticles before coating.

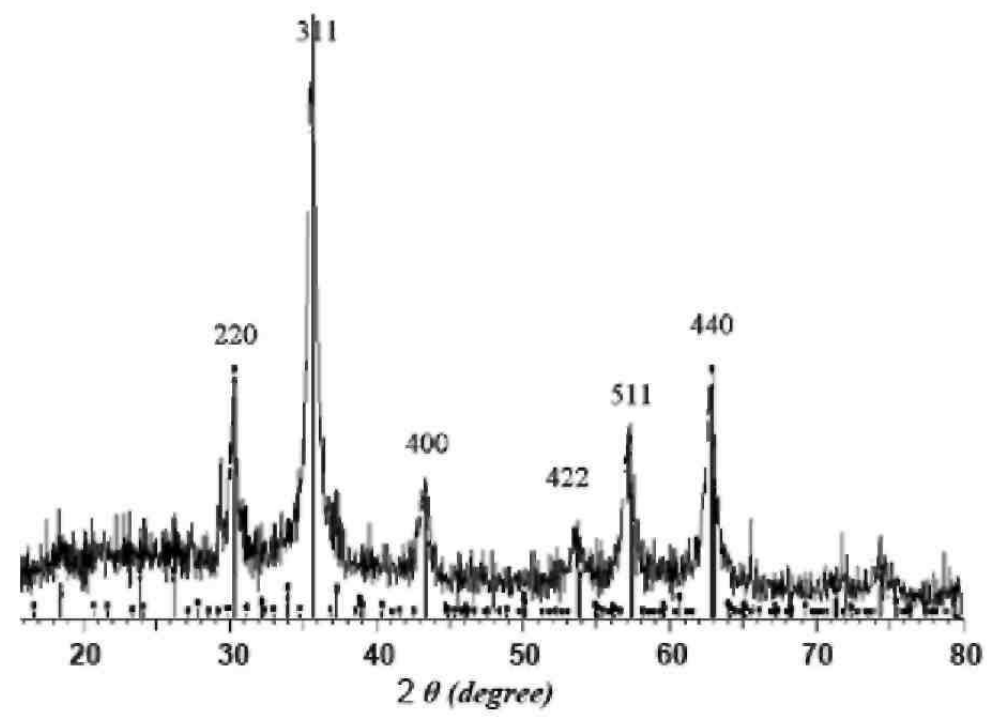

The ferrofluids were also characterized by dynamic light scattering (DLS). The average particle sizes accordingly measured for the uncoated NPs were much larger than those determined by TEM (50 nm). The reason has to be found in magnetostatic (magnetic dipole-dipole) interactions of the particles that cause their agglomeration even in the absence of an external magnetic field. This phenomenon was experimentally observed [40] and confirmed by Monte Carlo simulations, i.e., formation of closed rings and long open loops of particles without preferential spatial orientation. The aggregates have a lower diffusion coefficient than the single particle and the equivalent sphere radius measured by light scattering is higher than the elementary particle size as revealed by TEM (Fig. 2). In addition, the existence of a structured-water layer adjacent to the hydrophilic surface of MNPs can enhance the hydrodynamic radius measured by DLS as compared to TEM.

PAA-PEO copolymers are double hydrophilic block copolymers, that exhibit stimuli-responsive properties in water. Similarly to amphiphilic block copolymers that consist of two constitutive blocks of opposite philicity, they are prone to self-assembly into micelles by the appropriate tuning of the $\mathrm{pH}$. Holappa et al. reported indeed that at $\mathrm{pH}<4.5$, $\mathrm{PEO}$ and protonated polyacids spontaneously form water-insoluble intermolecular complexes by hydrogen bonding. Provided that PEO blocks are longer than PAA, micellar particles can be formed at low concentration. At higher $\mathrm{pH}$ (between 4.5 and 5.5), the partial ionization of the polyacids restricts the extent of the hydrogen bonding and intrachain interactions dominate, such that dilute solutions of contracted block copolymer chains can be observed. At $\mathrm{pH}>6$ the copolymer exhibits a fully extended coil conformation [41]. In this work, the PAA-PEO diblocks were used at $\mathrm{pH}=6.5$ in order to ionize the PAA blocks at the expense of 
complexation with PEO but at the benefit of interactions with the magnetite nanoparticles positively-charged at $\mathrm{pH} 4$ (Zeta potential $=45.7 \mathrm{mV}$ (Table 1$)$ ). So, upon mixing a solution at $\mathrm{pH} 6.5$ of an asymmetric PAA-PEO and the magnetite suspension at $\mathrm{pH} 4$, the copolymer and MNPs solutions $\mathrm{pH}$ reached 5.7 these nanoparticles were coated by a PEO shell (Scheme 2). DLS confirmed the stability of the coated magnetite nanoparticles that exhibited a narrow size distribution (Table 1). The increase in the hydrodynamic diameter of the original nanoparticles was qualitatively consistent with the effective coating. The diameter of the ferrofluids was $50 \mathrm{~nm}$ when coated by a PAA-PEO ligand and $40 \mathrm{~nm}$ in case of PAA-PAMPEO copolymer. In both cases, the diameter is smaller compared to determinations by DLS, presumably because TEM only shows the inorganic rich cores of the aggregates, and the presence of the PEO corona is not observed by TEM. A closer inspection of the TEM images shows micelles with several tens of magnetite NPs aggregated in the core and anisotropically distributed. It must be noted that the zeta potential of the magnetite nanoparticles changed drastically from positive to negative (Table 1), which can be explained by non ligated carboxylate groups at the surface [17,41,42]. Therefore, the two blocks of the copolymers contribute to the stabilization of the magnetite NPs by two mechanisms. Thanks the anchoring of the carboxylate groups with the surface of $\mathrm{Fe}_{3} \mathrm{O}_{4}$ nanoparticles, the PEO chains are immobilized at their surface and thus NPs are stabilized by a steric (entropic) repulsion of PEO chains. In addition to this, the electrostatic repulsion of the non ligated carboxylate groups at the NPs surface enhances the dispersion stability.

Fig. 5: Consumption of CH5O unit's vs. surface area of magnetite nanoparticles stabilized by different double hydrophilic block copolymers.

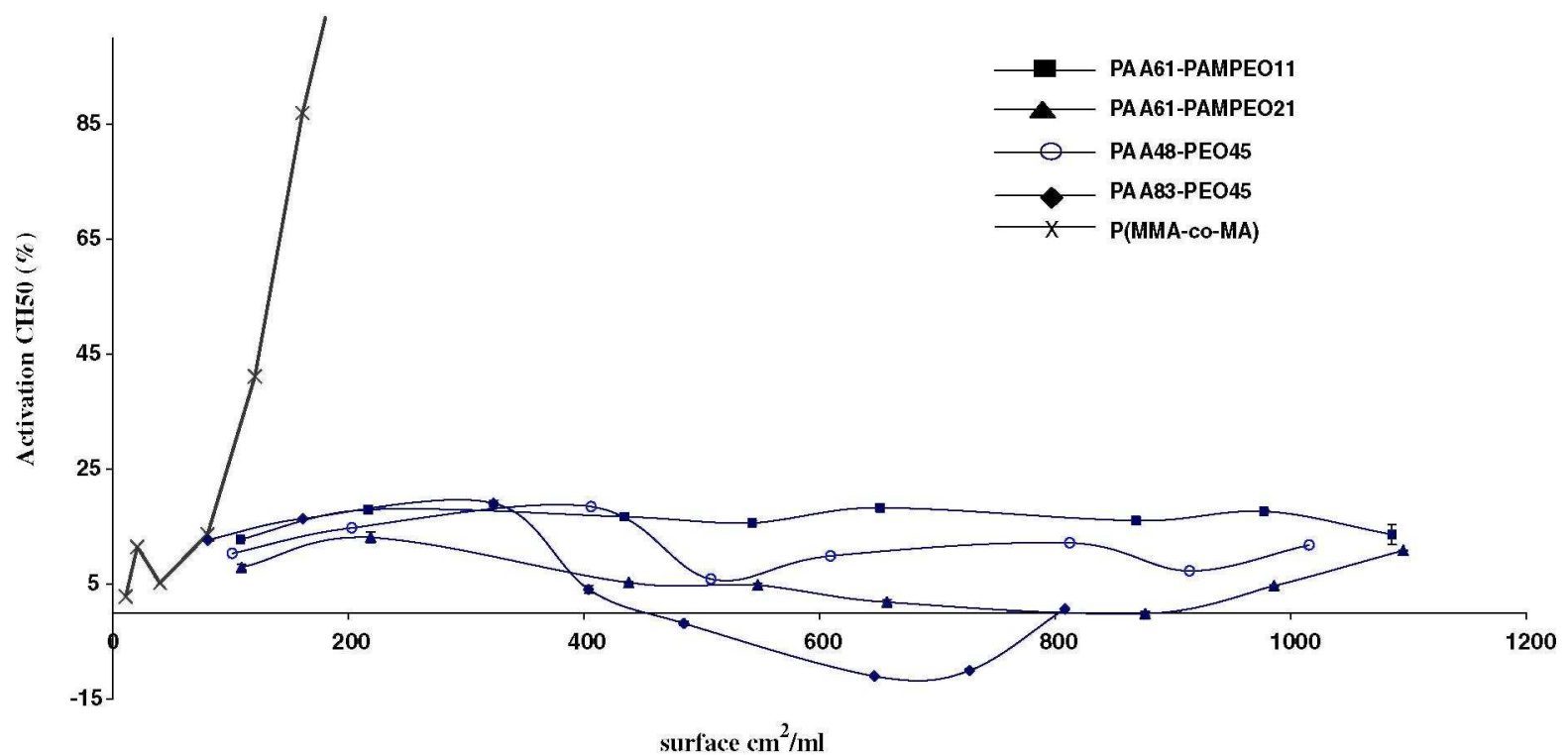

Fig. 6: Temperature increase triggered by magnetite nanoparticles in a magnetic field.

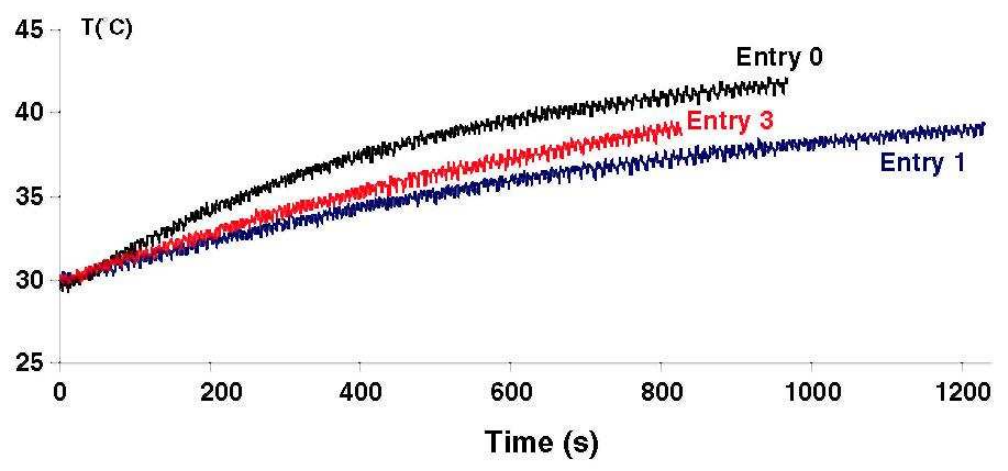




\subsection{Complement activation}

The stealthiness of the coated nanoparticles was assessed in vitro by the hemolytic CH50 test and compared to poly(methylmethacrylate-co-methacrylic acid) P(MMA-co-MA25) coated nanoparticles reported elsewhere [35]. This CH50 test is based on the activation of the complement system by the nanoparticles in normal human serum (diluted 1/4 (v/v)). The amount of serum proteins adsorbed on the NPs' surface decreases with increasing stealthiness. Basically, after exposure of the human normal serum to increasing amounts of nanoparticles, the amount of serum needed to haemolyse $50 \%$ of a fixed number of sensitized sheep erythrocytes was determined. The complement consumption was thus evaluated after incubation with nanoparticles stabilized by PAA-PEO and PAA-PAMPEO copolymers (Table 1, Fig. 5). In all cases, the nanoparticles did not trigger any response of the complement system, the activation being lower than $20 \%$ even for high surface contact $\left(>1000 \mathrm{~cm}^{2} / \mathrm{mL}\right)$. In contrast, the nanoparticles stabilized by the P(MMA-co-MA) copolymer adsorbed much larger amounts of serum proteins, being thus strong activators of the complement system. One hundred percent of CH50 units were indeed consumed when the serum protein solution was exposed to only $150 \mathrm{~cm}^{2}$ of nanoparticle surface. This comparison confirmed the unique capacity of PEO chains to prevent protein adsorption [35]. According to Fig. 5, the stealthiness of the NPs is independent of the architecture of the PEO blocks, i.e., single blocks vs. comb-shaped blocks. This observation is in apparent contradiction with a previous work by Rieger et al. who reported that a comb of shorter PEO chains was more beneficial than only one PEO chain of a higher molecular weight tethered to the NP's surface [35]. In that case, however, the average diameter of the NPs was much higher $(200 \mathrm{~nm})$ than in this work, consistently with stealthiness that increases when the size is decreased. The stealthiness of the uncoated magnetite NPs could not be analyzed because of their precipitation upon addition of the VBS++ solution, this can be considered as a clear indication of the magnetic NPs coating by the copolymers.

\subsection{Specific absorption rates}

Because superparamagnetic magnetite NPs generate heat by Néel and/or Brown relaxation losses in an alternating magnetic field [43], their use was reported for the heat ablation of tumors [44]. Therefore, the temperature profile of the magnetite nanoparticles used in this work was recorded (Fig. 6). Inductive heating experiments show that a magnetic field of $100 \mathrm{kHz}$ is able to produce enough energy for temperature to increase by approximately $10{ }^{\circ} \mathrm{C}$ within a short period of time. The specific absorption rates (SAR) are reported in Table 1. They were calculated by the expression $\mathrm{SAR}=\mathrm{C} \Delta T / \Delta t$, where $C$ is the sample specific heat capacity, which strongly depends on the weight of iron in the solution, and $\Delta T / \Delta t$ is the slope of temperature (from 36 to $38{ }^{\circ} \mathrm{C}$ ) vs. time. The higher value $\left(\sim 20 \mathrm{~W} / \mathrm{g}_{(\mathrm{Fe})}\right)$ was reported for the uncoated nanoparticles in good agreement with data in the scientific literature. The SAR value significantly decrease upon coating falling between 2 and $13 \mathrm{~W} / \mathrm{g}_{(\mathrm{Fe})}$. The application of the SAR equation requires the knowledge of the iron mass which has been determined by volumetric titration of the starting solution considering, in first approximation, that the further sampling of the starting solution distributes constant amount of iron in each sample.

\section{Conclusion}

A series of PAA-PEO block copolymers were synthesized by RAFT polymerization of acrylic acid in the presence of a macro-RAFT agent (PEO end-capped by a RAFT agent). A second series of PAA-PAMPEO block copolymers, in which PEO has a comb-architecture, was also prepared by sequential RAFT copolymerization of acrylic acid and the $\omega$-acrylate, $\alpha$-methoxy poly(ethylene oxide) macromonomers, with 2-dodecylsulfanylthiocarbonylsulfanyl-2-methyl propionic acid as a RAFT agent. These double hydrophilic block copolymers were able to stabilize magnetite nanoparticles prepared by co-precipitation of $\mathrm{Fe}^{2+}$ and $\mathrm{Fe}^{3+}$ in water. TEM, observations and DLS and zeta potential data confirmed that magnetic NPs were incorporated within the core of micelles with an average diameter lower than $100 \mathrm{~nm}$. The protective shell of PEO chains provided the nanoparticles with stealthiness in addition to stability. Moreover, they prevented any response of the complement system from responding. Although accurate data are not available yet, the ferrofluids prepared in this work should be source of heat when submitted to an alternating magnetic field.

\section{Acknowledgments}

AA, AR, RM, RJ and CJ are grateful to the 'Région Wallonne' for support in the frame of the "NOMADE" program. CJ and her co-workers are much indebted to the "Belgium Science policy" for general support to CERM in the frame of the PAI VI/27 program "Functional Supramolecular Systems". A.A. is much indebted to the european NoE "FAME" and to CGRI-FNRS-Inserm cooperation for grant supporting research stays in Bordeaux and Angers, respectively. 
Published in: European Polymer Journal (2008), vol. 44, iss. 10, pp. 3191-3199

Status: Postprint (Author's version)

\section{References}

[1] Murray CB, Kagan JR, Wendi MG. Science 1995;270:1335.

[2] Sundeen JE, Buchanan RC. Sens Actuators 1997;A63:33.

[3] Leslie-Pelecky DL, Rieke RD. Chem Mater 1996;8:1770-83.

[4] Phillips JP, Li C, Dailey JP, Riffle JS. J Magn Magn Mater 1999;194:140-8.

[5] Molday RS, MacKenzie D.J Immunol Methods 1982;52:353-67.

[6] Roath S. J Magn Magn Mater 1993;122:329-34.

[7] (a) Mornet S, Vasseur S, Grasset F, Duguet E. J Mater Chem 2004;14:2161-75;

(b) Duguet E, Mornet S, Vasseur S, Devoisselle JM. Nanomedicine 2006;1:257.

[8] Kim DK, Zhang Y, Kehr J, Klason T, Bjelke B, Muhammed M. J Magn Magn Mater 2001;225:256-61.

[9] Babes L, Denizot B, Tanguy G, Le Jeune JJ, Jallet P. J Colloid Interface Sci 1999;212:474-82.

[10] Papisov MI, Bogdanov AJ, Schaffer B, Nossiff N, Shen T, Weissleder R, et al. J Magn Magn Mater 1993;122:383-6.

[11] Widder K, Flouret G, Senyei A. J Pharm Sci 1979;68:79-82.

[12] Gupta PK, Hung CT, Lam FC, Perrier DG. IntJ Pharm 1988;43:167-77.

[13] Ibrahim A, Couvreur P, Roland M, Speiser P. J Pharm Pharmacol 1982;35:59-61.

[14] (a) Gould P. Materials Today 2004;7:36-43;

(b) Euliss LE, Grancharov SG, Brien SO, Deming TJ, Stucky GD, Murray CB, et al. Nano Letters 2003;3(11):1489-93.

[15] Pankhurst QA, Connolly J, Jones SK, Dobson J. J Phys D Appl Phys 2003;36:R167-81.

[16] Shourong W, Junsheng H, Husheng Y, Keliang L. J Mater Chem 2006;16:298-303.

[17] Harris LA, Goff JD, Carmichael AY, Riffle JS, Harburn JJ, St. Pierre TG, et al. Chem Mater 2003;15:1367-77.

[18] Iannone A Magin RL, Walczack T, Federico M, Swartz HM, Tomasi A, et al. Magn Reson Med 1991;22:435-42.

[19] (a) Massart R. IEEE Trans Magn 1999;17:1247;

(b) Bacri J, Perzynski R, Salin D, Cabuil V, Massart R. J Magn Magn Mater 1990;85:27-32.

[20] Khalafalla SE, Reimers GW. IEEE Trans Magn 1980;Mag-16:178-83.

[21] (a) Shen L, Stachowiak A Hatton TA, Laibinis PE. Langmuir 2000;16:9907-11;

(b) Thünemann A, Schütt D, Kaufher L, Pison U, Möhwald H. Langmuir 2006;22(5):2351-7.

[22] (a) Shen L, Stachowiak A, Seif-Eddeen KF, Laibinis PE, Hatton TA. Langmuir 2001;17:288-99;

(b) Bouyer F, Sanson N, Destarac M, Gérardin C. New J Chem 2006;30:399-408.

[23] Shimoiizaka J, Nakatsuka K, Fujita T, Kounosu A. IEEE Trans Magn 1980;MAG-16:368-71.

[24] (a) Wan S, Huang J, Yan H, Liu K. J Mater Chem 2006:298;

(b) Wan S, Zheng Y, Liu Y, Yan H, Liu K. J Mater Chem 2005;15:3424;

(c) Lee H, Lee E, Kim DK, Jang NK, Jeong YY, Jon S. J Am Chem Soc 2006;128:7383;

(d) Hu F, Wei L, Zhou Z, Ran Y, Li Z, Gao M. Adv Mat 2006;18:2553; 
Published in: European Polymer Journal (2008), vol. 44, iss. 10, pp. 3191-3199

Status: Postprint (Author's version)

(e) Wormuth K. J Colloid Interface Sci 2001;241:366-77;

(f) Lutz JF, Stiller S, Hoth A, Kaufher L, Pison U, Cartier R. Biomacromolecules 2006;7(11):3132-8.

[25] Pardoe H, Chua-anusorn W, St Pierre TG, Dobson J. J Magn Magn Mater 2001;225:41-6.

[26] Mendenhall GD, Geng Y, Hwang J. J Colloid Interface Sci 1996;184:519-26.

[27] Lee J, Isobe T, Senna M. J Colloid Interface Sci 1996;177:490-4.

[28] Palmacci S, Josephson L, Groman EV. PCT WO 9505669, 8/12/93.

[29] Ding XB, Sun ZH, Wan GX, Jiang YY. React Funct Polym 1998;38:11-5.

[30] Underhill RS, Liu G. Chem Mater 2000;12:2082-91.

[31] Wang P, Tan KL, Kang ET. J Biomater Sci Polym Edn 2000;11:169.

[32] (a) Passirani C, Benoit JP, Mahato RI, editors. Boca Raton, Florida, USA: CRC Press, Inc.; 2005 [chapter 6].

(b) Mayer MM, Kabat EA, Mayer MM, editors. IL, USA: Springfield; 1961. p. 133

[33] (a) Lee JH, Lee HB, Andrade JD. Prog Polym Sci 1995;20:1043;

(b) Torchilin VP. Adv Drug Deliv Rev 2002;54:235.

[34] (a) Vittaz M, Bazile D, Spenlehauer G, Verrechia T, Veillard M, Puisieux F, et al. Biomaterials 1996;17:1575;

(b) Peracchia MT, Vauthier C, Passirani C, Couvreur P, Labarre D. Life Sci 1997;61:749;

(c) Passirani C, Barratt G, Devissaguet JP, Labarre D. Life Sci 1998;62:775

(d) Passirani C, Benoît JP, Mahato RI, editors. Florida, USA: CRC Press; 2005. p. 187-230.

[35] (a) Rieger J, Passirani C, Benoit JP, Van Butsele K, Jerome R, Jerome C. Adv Funct Mat 2006;16(11):1506-14(b) Aqil A, Vasseur S, Duguet E, Passirani C, Benoît JP, Jérôme R, Jérôme C. J. Mater. Chem., 2008, doi: 10.1039=b804003f.

[36] (a) Kabanov A, Bronich T, Kabanov V, Yu K, Eisenberg A. Macromolecules 1996;29:6797;

(b) Bronich T, Kabanov A, Kabanov V, Yu K, Eisenberg A. Macromolecules 1997;30:3519;

(c) Wang J, Varshney S, Jerome R, Teyssie P. J Polym Sci Part A Polym Chem 1992;30(10):2251.

[37] Guillemet B, Faatz M, Gröhn F, Wegner G, Gnanou Y. Langmuir 2006;22:1875-9.

[38] Aqil A, Detrembleur C, Gilbert B, Jérôme R, Jérôme C. Chem Mat 2007;19:2150-4.

[39] Lai JT, Filla D, Shea R Macromolecules 2002;35:6754.

[40] Maity D, Agrawal DC. J Magn Magn Mat 2007;308:46-55.

[41] Holappa S, Kantonen L, Winnik FM, Tenhu H. Macromolecules 2004;37:7008-18.

[42] Stoffelbach F, Aqil A, Jérôme C, Jérôme R, Detrembleur D. Chem Commun 2005:4532-3.

[43] Ma M, Wu Y, Zhou J, Sun Y, Zhang Y, Gu N. J Magn Magn Mater 2004;268:33.

[44] Hilger I, Hiergeist R, Winnefeld K, Schubert H, Kaiser WA. Invest Radiol 2002;37:580. 